\title{
The Neurochemistry of Therapeutics: Levodopa Pharmacodynamics in Parkinson's Disease
}

Parkinson's disease (PD), the most common neurodegenerative movement disorder, has enjoyed a recent explosion of treatment options available for its symptomatic management. Despite these recent introductions, PD remains a progressive disorder, with the majority of patients experiencing significant disability in its more advanced stages. One aspect of PD leading to disability is the development of unsatisfactory symptomatic responses to precursor loading therapy with levodopa (LD). Typical PD patients respond initially to LD with a sustained (several hours) improvement in resting tremor, bradykinesia, and rigidity. This response initially outlasts the plasma levels of LD and has been assumed to rely on conversion to dopamine in remaining striatal monoaminergic terminals, with subsequent storage in and release from synaptic vesicles. In more advanced $\mathrm{PD}$, the response from an individual dosage becomes progressively shortened until it closely parallels the plasma LD level. Furthermore, the clinical response to LD in advanced PD is often complicated by unpredictable losses of therapeutic effect and by choreoathetoid dyskinesias at times of peak LD effect. There is limited mechanistic understanding of these complications, with attendant controversy surrounding the relationship of prior medication history to their risk of development. In the present issue of The $A n$ nals, de la Fuente-Fernandex et al have applied positron emission tomography (PET) to the investigation of levodopa pharmacodynamics in PD patients with regard to the subsequent development of end-ofdosage "wearing off" of LD effect. ${ }^{1}$

The studies reported by de la Fuente-Fernandez et al are based mechanistically on prior investigations from a number of laboratories that have identified apparent effects of endogenous neurotransmitter on the in vivo binding of dopamine $\mathrm{D}_{2}$-type receptor antagonist radioligands $^{2-4}$ (see Laurelle for a recent review). Initial studies suggesting an effect of endogenous dopamine on binding of $\mathrm{D}_{2}$ antagonists such as $\left[{ }^{11} \mathrm{C}\right]$ raclopride (RAC) and $\left[{ }^{123} \mathrm{I}\right]$ iodobenzamide employed interventional challenges with the dopamine releaser amphetamine. Paired, within-subject studies demonstrated significant reductions in RAC binding after intravenous amphetamine compared to baseline in normal subjects. Detailed investigations of this effect in nonhuman primates indicate that the magnitude of the PET binding reduction correlated with the magnitude of dopamine release, as assessed by in vivo microdialysis. ${ }^{6,7}$ Further evidence in support of the role of endogenous dopamine as the mediator of the effect is the observation that it is abolished by prior dopamine depletion., ${ }^{2,6}$

Human patient studies employing the amphetamine challenge paradigm indicate potential presynaptic dopaminergic abnormalities in neuropsychiatric disorders. Several investigators have examined the effect of amphetamine on $\mathrm{D}_{2}$ receptor binding in schizophrenic patients. ${ }^{8,9}$ In comparison to normal control subjects, schizophrenics frequently demonstrate exaggerated responses (greater reduction of $\mathrm{D}_{2}$ radioligand binding after amphetamine), suggesting increased presynaptic dopamine stores or abnormal regulation of synaptic dopamine disposition. In addition, dopamine depletion after alphamethyltyrosine administration reveals increased $\mathrm{D}_{2}$ radioligand binding in schizophrenics that exceeds that in normal subjects, suggesting increased $\mathrm{D}_{2}$ receptor occupancy at baseline in unmedicated schizophrenia. ${ }^{10}$ Although findings are only preliminary, the possibility of altered presynaptic dopaminergic regulation in Tourette syndrome is supported by exaggerated amphetamine response in $\mathrm{D}_{2}$ radioligand imaging studies as well. ${ }^{11}$

Can apparent synaptic dopamine changes induced by interventions other than amphetamine be measured by the $\mathrm{D}_{2}$ receptor radioligand binding competition paradigm? Amphetamine administration results acutely in up to 100-fold increases in dopamine release from nerve terminals compared with baseline levels. Thus, it is reasonable to question whether more modest stimuli have detectable effects on the in vivo binding of RAC. To the affirmative, investigators have demonstrated similar apparent competitive effects of dopamine reuptake inhibitors such as methylphenidate. ${ }^{12}$ Furthermore, it has been observed that putative trans-synaptic effects of acetylcholine, ${ }^{13}$ serotonin, ${ }^{14}$ and glutamate ${ }^{15,16}$ modulations lead to altered in vivo RAC binding, presumed to be mediated by the competitive effect of endogenous dopamine. Finally, Tedroff et $\mathrm{al}^{17}$ have demonstrated previously in PD that acute administrations of LD result in decreased RAC binding (Fig). It is this specific competitive radioligand-binding paradigm that was investigated further by de la FuenteFernandez et al. 
A
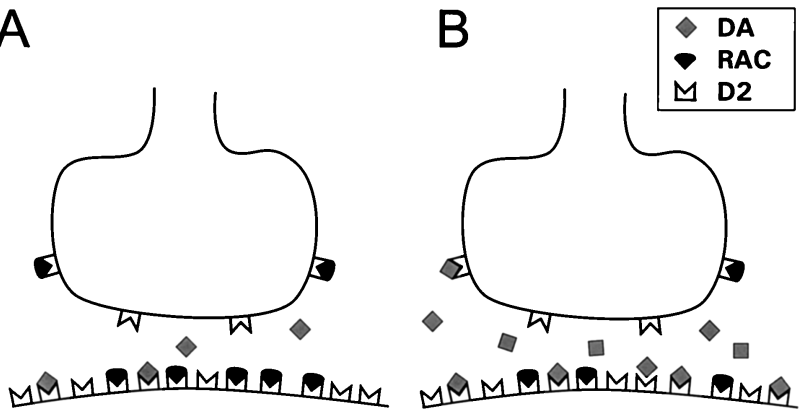

Fig. Schematic diagram of $L D$ effect on in vivo RAC binding at nigrostriatal synapses. In the baseline state $(A)$, there is limited occupancy of dopamine $D_{2}$ receptors by $D A$, and $R A C$ binding identifies the population of free receptors. After administration of $L D$, there are increased synthesis and release of $D A$, leading to fewer free $D_{2}$ receptors and then to reduced $R A C$ binding. Comparison of the pre- and post- $L D R A C$ binding yields an index of $D A$ effect. $D A=$ dopamine; $R A C=\left[{ }^{11} C\right]$ raclopride; $D_{2}=$ dopamine $D_{2}$-type receptor.

The study reported by de la Fuente-Fernandez et al in this issue examined the effects of oral LD on RAC in PD patients with stable therapeutic responses. The time course of presumed competitive synaptic dopamine resulting from oral $\mathrm{LD}$ was assessed by serial PET measures before and at 1 and 4 hours after LD dosage. All patients had continued therapeutic response through 4 hours, and none had peak dosage dyskinesias or end-of-dosage wearing-off phenomena at the time of PET study. Subsequent 3-year clinical follow-up revealed development of end-of-dosage wearing off in half of the subjects. Comparison of the subsets with and without wearing off revealed significant differences in the LD effect on RAC. Patients who developed wearing off demonstrated greater reduction of RAC at 1 hour after LD but had return to baseline by 4 hours. Patients without wearing off 3 years later had smaller LD effects on RAC at 1 hour but maintained the effect for 4 hours. Thus, the authors conclude that LD pharmacodynamics predict the development of wearing off years before its clinical expression.

Must altered presynaptic LD or subsequent dopamine disposition and metabolism alone account for the observed PET findings? De la Fuente-Fernandez et al interpret their findings as indicative of differences in synaptic dopamine levels and time courses in the two PD patient groups. While this is a satisfactory explanation, there are alternatives. Additional possibilities are changes in $\mathrm{D}_{2}$ receptor subcellular distribution or coupling. The amphetamine-induced changes discussed previously, although mediated by endogenous dopamine, display a protracted temporal profile that outlasts by hours the induced dopamine release. Converging evidence now suggests that this is explained by internalization of the $\mathrm{D}_{2}$ receptors after amphetamine, with reduced affinity of RAC for the internalized $\mathrm{D}_{2}$ binding sites. ${ }^{5}$ Internalization is not a likely explanation for the present findings, since the effect is of short temporal duration in the wearing-off subgroup. In addition, dopamine receptors display multiple affinities for agonists, reflecting their state of coupling to $G$ protein second-messenger effectors. ${ }^{18}$ The observed effect of LD could preferentially involve high-affinity-state $\mathrm{D}_{2}$ receptors, and this could change in response to the synaptic dopamine level. Another question regards the inference that there may be increased initial synaptic dopamine levels in the wearing-off group versus the stable LD responders. Again, the authors' interpretation is plausible, but differential levels of dopamine and of dopamine receptors at baseline could also lead to a similar distinction. Prior studies of Antonini et $\mathrm{al}^{19}$ indicate increased RAC binding in the striata of medication-naïve PD patients. After initiation of therapy, RAC binding is reduced to or even below the normal range. These findings have been interpreted as depicting denervation-related upregulation of $\mathrm{D}_{2}$ receptor expression in unmedicated PD but could alternatively be due to removal of the competitive effect of dopamine, as demonstrated in normal control subjects after dopamine depletion. Thus, the exaggerated LD effect observed by de la Fuente-Fernandez et al in patients with wearing off could be related to more severe baseline depletion of dopamine or to altered $\mathrm{D}_{2}$ receptor populations as well as to the posited change in synaptic LD.

The present report by de la Fuente-Fernandez et al represents an exciting initial approach to study of LD pharmacodynamics and sets the stage for future RAC PET investigations of complex LD responses in PD. Complications, including both end-of-dosage wearing off and the more disabling LD-related dyskinesias, may ultimately be mechanistically defined by such studies. Furthermore, it may be possible to employ this new PET approach as an objective measure of PD evolution and its possible differential response to therapeutic alternatives.

Kirk A. Frey, $M D, P h D$

Departments of Radiology (Division of Nuclear Medicine) and Neurology University of Michigan

Ann Arbor, MI

\section{References}

1. de la Fuente-Fernandez R, Lu J-Q, Sossi V, et al. Biochemical variations in the synaptic level of dopamine precede motor fluctuations in Parkinson's disease: PET evidence for increased dopamine turnover. Ann Neurol 2001;49:298-303.

2. Innis RB, Malison RT, al-Tikriti M, et al. Amphetaminestimulated dopamine release competes in vivo for $\left[{ }^{123} \mathrm{I}\right] \mathrm{IBZM}$ binding to the $\mathrm{D}_{2}$ receptor in nonhuman primates. Synapse 1992;10:177-184.

3. Volkow ND, Wang G-J, Fowler JS, et al. Imaging endogenous dopamine competition with $\left[{ }^{11} \mathrm{C}\right]$ raclopride in the human brain. Synapse 1994;16:255-262. 
4. Laruelle M, Abi-Dargham A, van Dyck CH, et al. SPECT imaging of striatal dopamine release after amphetamine challenge. J Nucl Med 1995;36:1182-1190.

5. Laruelle M. Imaging synaptic neurotransmission with in vivo binding competition techniques: a critical review. J Cereb Blood Flow Metab 2000;20:423-451.

6. Laruelle M, Iyer RN, al-Tikriti MS, et al. Microdialysis and SPECT measurements of amphetamine-induced dopamine release in nonhuman primates. Synapse 1997;25:1-14.

7. Endres CJ, Kolachana BS, Saunders RC, et al. Kinetic modeling of $\left[{ }^{11} \mathrm{C}\right]$ raclopride: combined PET-microdialysis studies. J Cereb Blood Flow Metab 1997;17:932-942.

8. Laurelle M, Abi-Dargham A, van Dyck CH, et al. Single photon emission computerized tomography imaging of amphetamine-induced dopamine release in drug-free schizophrenic subjects. Proc Natl Acad Sci USA 1996;93:9235-9240.

9. Breier A, Su TP, Saunders R, et al. Schizophrenia is associated with elevated amphetamine-induced synaptic dopamine concentrations: evidence from a novel positron emission tomography method. Proc Natl Acad Sci USA 1997;94:2569-2574.

10. Abi-Dargham A, Rodenhiser J, Printz D, et al. Increased baseline occupancy of $\mathrm{D}_{2}$ receptors by dopamine in schizophrenia. Proc Natl Acad Sci USA 2000;97:8104-8109.

11. Szymanski S, Galiano J, Yokoi F, et al. Basal ganglia dopamine release in Tourette syndrome. J Nucl Med 1997;37(suppl):12P.

12. Volkow ND, Wang G-J, Fowler JS, et al. Reinforcing effects of psychostimulants in humans are associated with increases in brain dopamine and occupancy of $\mathrm{D}(2)$ receptors. J Pharmacol Exp Ther 1999;291:409-415.

13. Dewey SL, Smith GS, Logan J, et al. Effects of central cholinergic blockade on striatal dopamine release measured with positron emission tomography in normal human subjects. Proc Natl Acad Sci USA 1993;90:11816-11820.

14. Smith GS, Dewey SL, Brodie JD, et al. Serotonergic modulation of dopamine measured with $\left[{ }^{11} \mathrm{C}\right]$ raclopride and PET in normal human subjects. Am J Psychiatry 1997;154:490-496.

15. Breier A, Adler CM, Weisenfeld N, et al. Effects of NMDA antagonism on striatal dopamine release in healthy subjects: application of a novel PET approach. Synapse 1998;29:142-147.

16. Smith GS, Schloesser R, Brodie JD, et al. Glutamate modulation of dopamine measured in vivo with positron emission tomography (PET) and ${ }^{11} \mathrm{C}$-raclopride in normal human subjects. Neuropsychopharmacology 1998;18:18-25.

17. Tedroff J, Pedersen M, Aquilonius SM, et al. Levodopainduced changes in synaptic dopamine in patients with Parkinson's disease as measured by $\left[{ }^{11} \mathrm{C}\right]$ raclopride displacement and PET. Neurology 1996;46:1430-1436.

18. Creese I, Sibley DR, Hamblin MW, Leff SE. The classification of dopamine receptors: relationship to radioligand binding. Ann Rev Neurosci 1983;6:43-71.

19. Antonini A, Schwarz J, Oertel WH, et al. $\left[{ }^{11} \mathrm{C}\right]$ Raclopride and positron emission tomography in previously untreated patients with Parkinson's disease: influence of L-dopa and lisuride therapy on striatal dopamine $\mathrm{D}_{2}$-receptors. Neurology 1994;44: $1325-1329$. 